\title{
Vacuum assisted flow initiation in arching powders
}

\author{
R. Baserinia ${ }^{1}$, I.C. Sinka ${ }^{1}$ and P. Rajniak ${ }^{2}$ \\ ${ }^{1}$ Department of Engineering, University of Leicester, UK \\ ${ }^{2}$ Research Center Pharmaceutical Engineering (RCPE) GmbH, Graz, Austria
}

Corresponding author:

Dr. Csaba Sinka, tel. +44 116252 2555, fax +44 116 2522525, e-mail ics4@le.ac.uk

\section{Graphical abstract}

Vacuum assisted flow initiation testing device

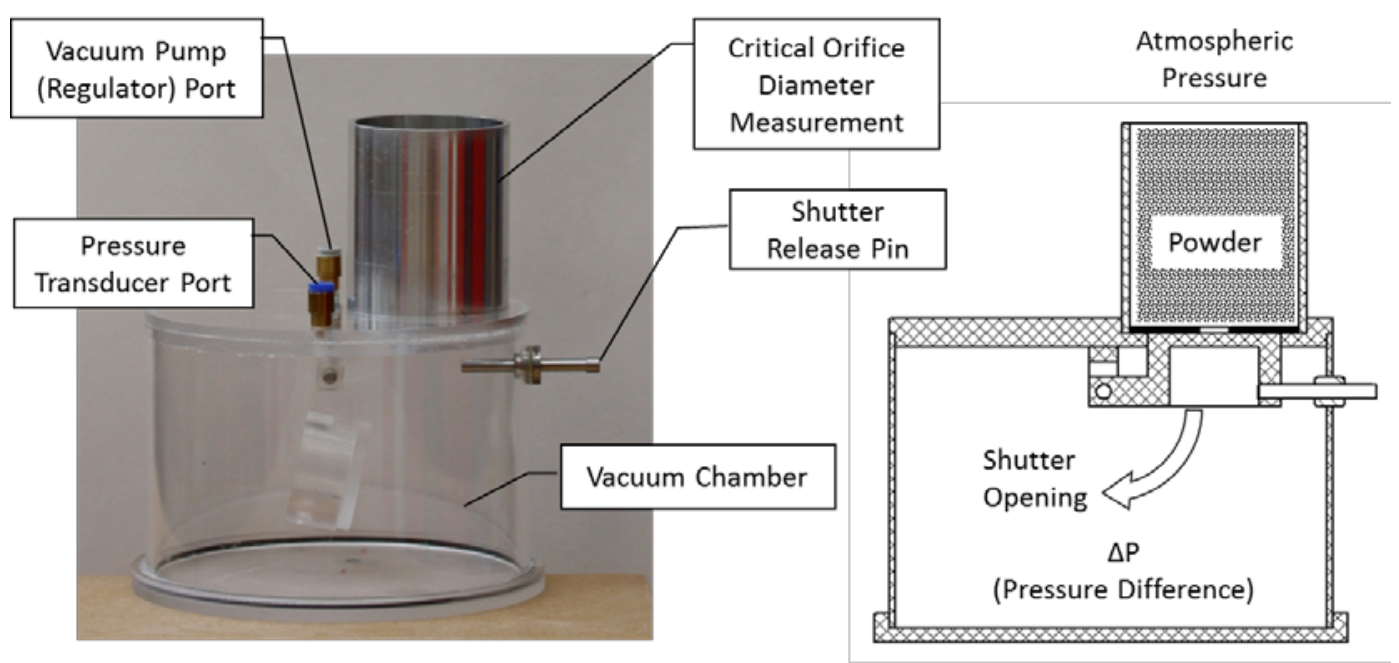

$\begin{aligned} & \text { Differential pressure required for flow } \\ & \text { initiation from an arching state: }\end{aligned} \frac{\Delta P}{\rho_{b} g d}=C\left(\frac{H}{D}\right)^{n}$

\section{Highlights}

- Vacuum applied at the exit of an arching hopper assists flow initiation.

- A small reduction of pressure changes the critical orifice diameter significantly.

- A dimensional model was developed to predict the pressure required to initiate flow. 


\begin{abstract}
The discharge of powders from hoppers usually takes place in open atmosphere. However, in powder pressing industries (e.g. manufacturing of pharmaceutical tablets, detergents, ceramics, powder metallurgy etc.) there are handling operations where powders are filled into closed cavities such as dies. During this process the air pressure is increased as powder is delivered into the die. At the same time typical tablet production equipment creates a suction effect. A critical orifice measurement apparatus was developed to study powder flow initiation from an arching state into an enclosure where the air pressure is reduced. It was shown that a very small reduction of pressure changed the critical orifice diameter significantly. Dimensional analysis was carried out to relate powder properties (particle size and density) and processing parameters (geometry of the system and differential pressure necessary to break the arch). A relationship was developed to calculate the pressure difference necessary to initiate powder flow. The relationship has two empirical parameters which are calibrated by performing simple experiments using the testing rig developed.
\end{abstract}

\title{
Keywords
}

Critical orifice, vacuum, flow initiation, model

\section{Introduction}

Filling and discharge from silos, hoppers and bunkers are important for high volume process industries such as mining and mineral processing, construction, energy, agriculture, food and for high value added processing industries such as pharmaceuticals and fertilizers.

Theoretical models to calculate the mass flow rate from bins and hoppers were developed in the late 1950s [1-3]. The model of Rose and Tanaka [2] includes parameters which allows it to be used for bins as well as hoppers. The model of Beverloo et al. [4] is still widely used to calculate mass flow rate in core flow bins as a function of orifice diameter and particle size. The models above were developed for "free" flowing powders and granular materials.

"Arching" occurs when particles interlock above the exit diameter and form a stable arch. This phenomenon presents significant technical challenges for handling and dosing of both free flowing and cohesive powders. Typically arching occurs when the exit diameter is smaller than a "critical orifice diameter", which can be measured using standard equipment [5]. Podczeck and Jones [6] use critical orifice diameter as a measure of the ability of a powder to form an arch while others [7] use it to describe flowability whereby a better flowing powder has a smaller critical orifice diameter.

There are a range of testing methods developed for measuring powder flowability including angle of repose, Carr's index and Hausner ratio (based on bulk and tapped density of powder) [5], flow rate through orifice, and shear cells $[5,8,9]$. These techniques are based on different principles and are used for specific applications. 
The angle of repose is one of the simplest measures of powder flowability and consists of discharging a powder from a hopper onto a flat surface and determining the angle between the heap and the horizontal base. A poor flowing powder forms a steep angle while a good flowing powder spreads more forming a smaller angle. However, the heap can be created in different ways, e.g. by fixing the height or the diameter as prescribed by USP [5] or ASTM [10]. In a classification proposed by Carr [11] materials vary from "excellent" to "very, very poor" flowability, where the angle of repose varies from 25-30 degrees to over 66 degrees, respectively. There are some variations from this classification but much of the pharmaceutical literature uses Carr's classification [5]. Other methods for measuring the angle of repose include: 1) the "drained" angle of repose, which is determined by measuring the angle of the slope of the powder remaining in the bin - this angle depends on the shape of container $[9,12]$; 2) the semi-cone angle formed between a base and a right angle wall [13]; 3) the tilting table [13]; 4) the dynamic angle of repose [12] where the angle of the powder in a rotating cylinder is determined; 5) scoop deposition [14]; 6) the cone lifting method [15]; and 7) measuring the angle of repose in liquid medium [16]. There is no general agreement on the best design or size of the equipment or the amount of powder that should be used for testing [17]. Lee et al. [18] compared the critical orifice diameter results with Carr's index and the dynamic angle of repose and observed that there are some similarities in classification of powder flowability between these techniques.

In a method developed by Hassanpour and Ghadiri [19] a ball indenter is used to determine the yield stress of powder sample compacted under low stress. This yield stress along with the consolidation stress is used to determine the Jenike's flow factor [20] and classify powders in terms of flowability.

The stress conditions leading to arching in hoppers have been studied extensively since the 1960s. Jenike's investigation $[20,21]$ lead to development of a model to calculate the geometry of a mass flow hopper in order to avoid arch formation. Walker's theoretical studies [7] determined the approximate stresses within the powder flowing through a hopper. Drescher and co-workers [22, 23] compared the experimental critical orifice sizes with the values obtained from theoretical analysis and demonstrated that the theories overestimate the critical orifice size as a result of neglecting selfweight of powder above the exit.

The importance of air pressure conditions have been documented since the 1970s. Shinohara [24] constructed a theoretical model validated by experiments which shows that the flow rate of cohesive powders is facilitated by positive air pressure above the hopper as well as negative pressure at the outlet. Similar to the Beverloo equation Bulsara [25] developed a model that considered the air pressure above and below the powder bed as well as the pore pressure in the powder just above the orifice.

The flow of powder from hoppers is usually assumed to take place in open atmosphere. However, in powder pressing industries (e.g. pharmaceutical tablets, detergents, ceramics, powder metallurgy etc.) the powders are filled into closed cavities; this is followed by compaction using rigid punches and finally the product is ejected from the die. During die fill the air pressure is increased as the powder is introduced into the die. The interplay between powder and air during die fill has been studied using model shoe-die systems [26, 27]. Models for mass flow rate have been developed [28] prompting further research on air pressure effects in die fill $[29,30]$, and on understanding suction fill mechanisms. 
These mechanisms are essential for practical manufacturing processes. For example a typical pharmaceutical tablet has a diameter smaller than $10 \mathrm{~mm}$. A typical pharmaceutical formulation has a critical orifice diameter larger than $10 \mathrm{~mm}$. This poses a simple question: how is die fill possible? Jackson et al. [29] identified qualitatively the effect of differential pressure on this process.

This paper presents quantitative studies on the effect of differential pressure conditions at the exit from an arching bin on flow initiation. A critical orifice diameter measurement apparatus was developed whereby the powder is discharged into a chamber with controlled pressure. The sensitivity of critical orifice diameter to air pressure at the exit is investigated. A dimensional model is developed to determine the pressure required for flow initiation as a function of orifice diameter and powder properties.

\section{Materials}

Four grades of microcrystalline cellulose, Avicel PH101, PH102, PH200 and PH302 (manufactured by FMC BioPolymer) are used in this study. The properties of these powders are summarised in Table 1. These materials have been chosen because they are commonly used excipients in pharmaceutical tablet formulation. The particles have the same morphology [31] which allows investigating the effect of particle size and bulk density on flow behaviour. PH101, PH102 and PH200 have almost the same bulk densities-while $\mathrm{PH} 102$ and $\mathrm{PH} 302$ have same nominal size but different densities.

Scanning Electron Microscope - SEM - (XL30 ESEM manufactured by Philips) images of the four powders are presented in Figure 1. 

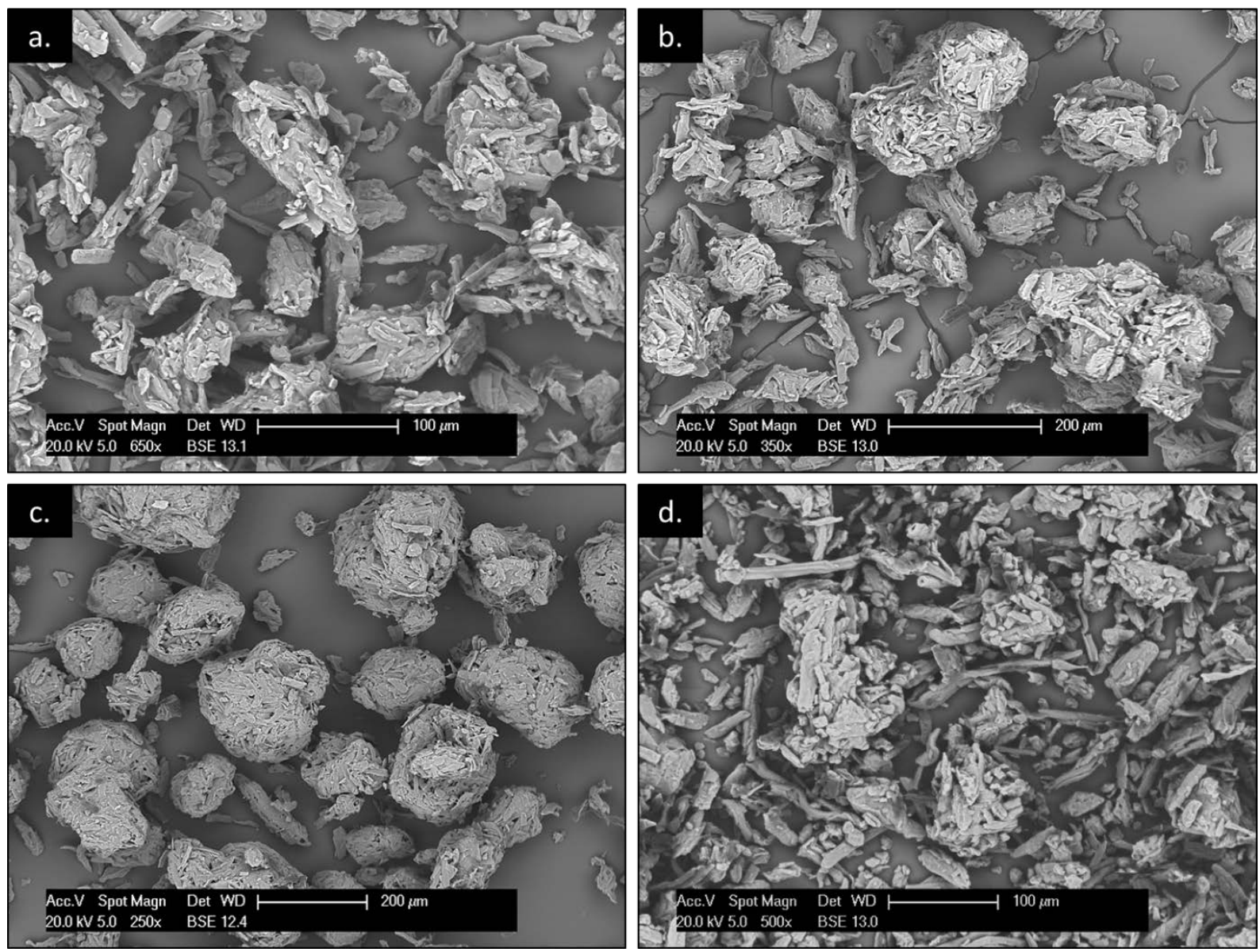

Figure 1. SEM images of a) PH101, b) PH102, c) PH2O0 and d) PH302

Table 1. Properties of four grades of microcrystalline cellulose (from manufacturer specifications)

\begin{tabular}{|c|c|c|c|}
\hline Material & $\begin{array}{c}\text { Bulk Density } \\
(\mathrm{g} / \mathrm{ml}) \mathrm{min}\end{array}$ & $\begin{array}{c}\text { Bulk Density } \\
(\mathrm{g} / \mathrm{ml}) \mathrm{max}\end{array}$ & $\begin{array}{c}\text { Mean } \\
\text { Particle size } \\
(\mu \mathrm{m})\end{array}$ \\
\hline PH101 & 0.26 & 0.31 & 50 \\
\hline PH102 & 0.28 & 0.33 & 100 \\
\hline PH200 & 0.29 & 0.36 & 200 \\
\hline PH302 & 0.35 & 0.46 & 100 \\
\hline
\end{tabular}

\section{Experimental procedures}

The flow properties of powders were measured using standard methods, such as angle of repose, bulk density and critical orifice diameter. The procedures follow USP29-NF24 [5] using in-house built devices. To investigate air pressure effects, the critical orifice measurement apparatus was further developed to enable control of the air pressure at exit as described in Section 3.4. 


\subsection{Angle of Repose}

The device used to measure the angle of repose is illustrated in Figure 2 and consists of a cylindrical base, a funnel and a powder conditioning device. The base allows creating heaps with precise diameters of 50,75 or $100 \mathrm{~mm}$. The funnel conforms to the geometry of the Hall flowmeter [32]. The powder conditioning device is also adapted from the Scott Volumeter [5] procedure and is employed to ensure consistent and repeatable filling of the hopper.

The procedure consists of lowering the funnel to touch the base, filling the funnel with $75 \mathrm{~g}$ of powder and raising the funnel gradually so that the powder is discharged and forms a heap with a given base diameter. The height of the heap is measured and the angle of repose is calculated. This procedure was repeated five times (using a fresh sample of powder for each repeat experiment) for each of the four materials using the three different base diameters.

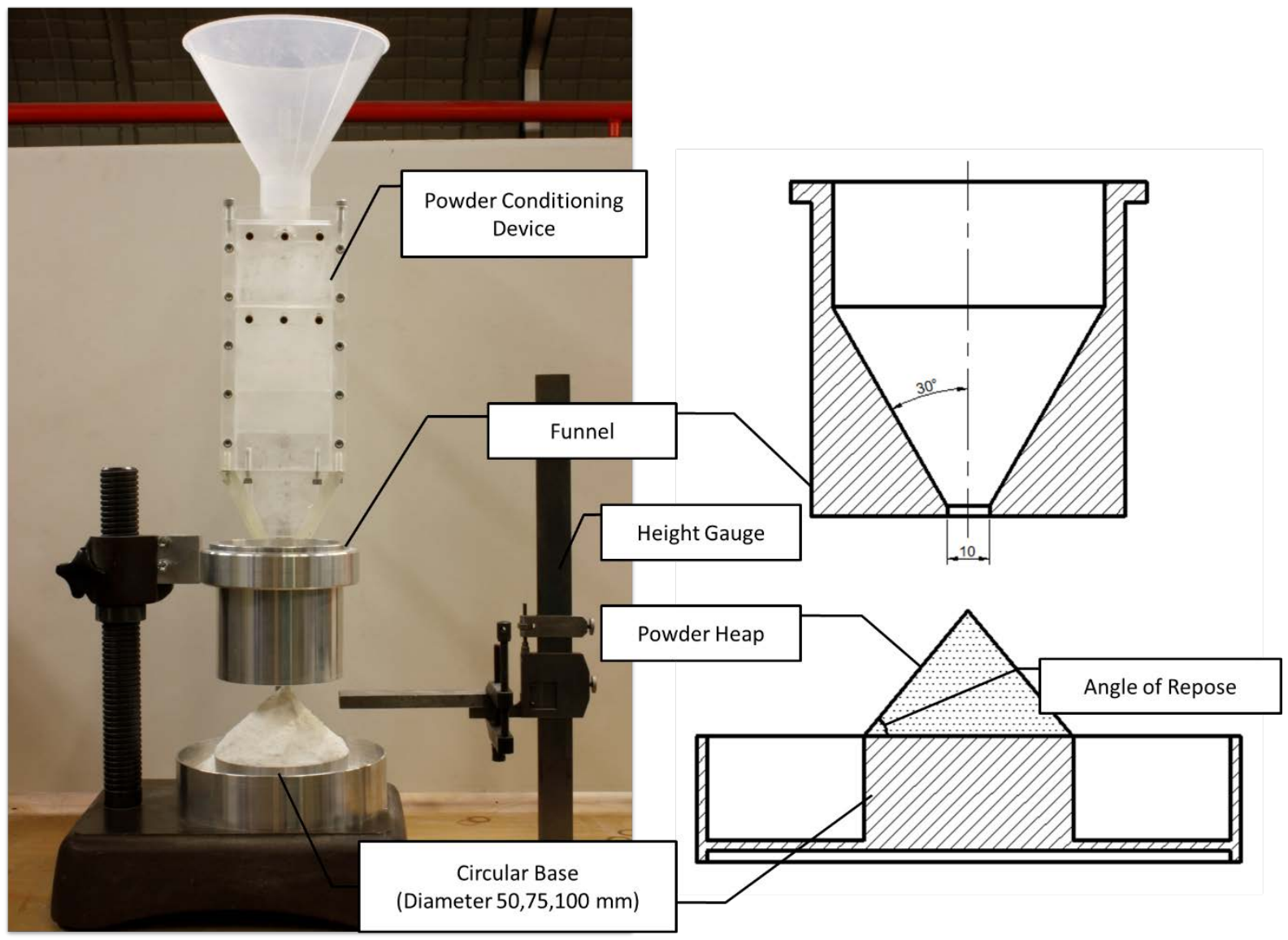

Figure 2. Angle of repose measurement apparatus

\subsection{Bulk density}

In order to measure bulk density, the powder was introduced into a cup with internal diameter of $D=$ $57.4 \mathrm{~mm}$ and height of $H=76 \mathrm{~mm}$ using the powder conditioning device (Figure 3). Once the container was full, the hip formed on the top was removed using a horizontal blade and the mass of the powder in the cylinder was measured. Using the volume of the cylinder, the bulk density was determined. Ten repeat experiments were carried out for each powder (using a fresh sample of powder for each repeat experiment). 


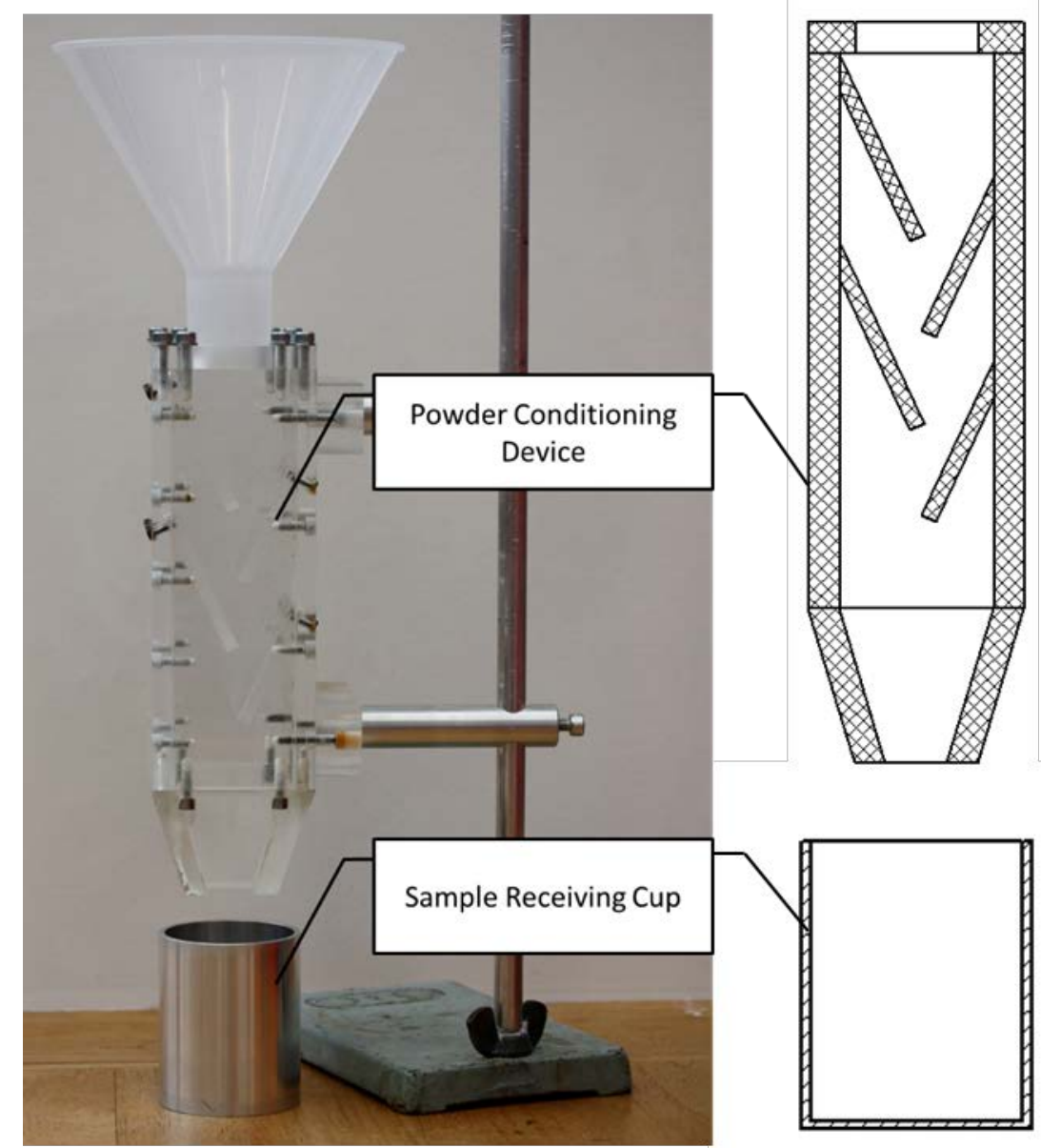

Figure 3. Bulk density measurement set-up

\subsection{Critical orifice diameter}

The cylindrical container with internal diameter of $D=57.4 \mathrm{~mm}$ and height of $H=75 \mathrm{~mm}$ was closed using a shutter as indicated in Figure 4 . A set of 24 disks with opening diameters between 1 and $30 \mathrm{~mm}$ were used starting with the largest $(30 \mathrm{~mm})$ opening. The disk was placed in the cylinder above the shutter and the cylinder was filled with powder. The excess powder above the cylinder rim was removed using a horizontal blade. The shutter was opened using the release pin. If powder flow out of the cylinder was observed the experiment was repeated using a disk with a smaller orifice diameter. The smallest orifice diameter from which the powder discharged was recorded as the critical orifice diameter. Five repeat experiments were carried out (using a fresh sample of powder for each repeat experiment) to confirm the critical orifice diameter. 


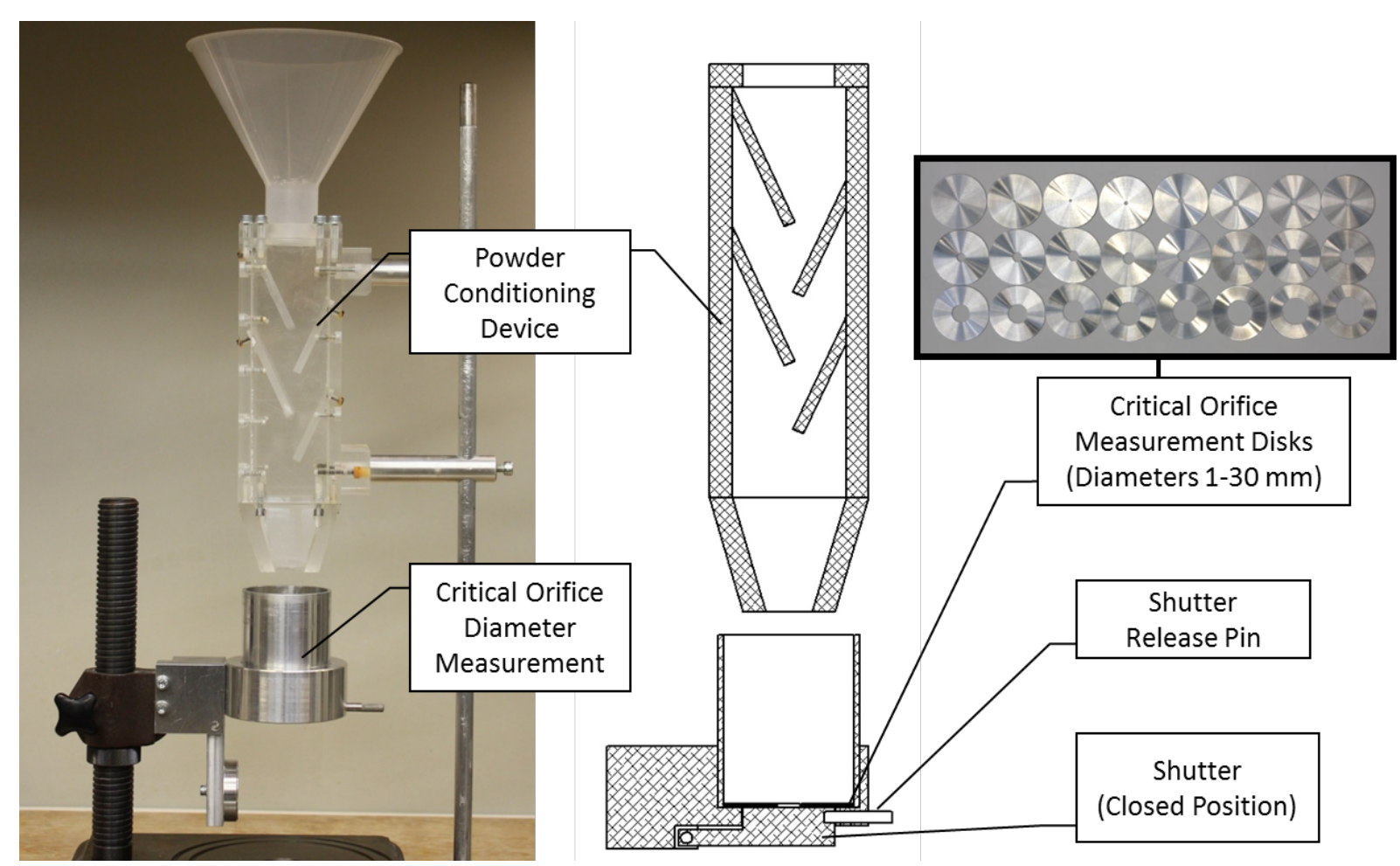

Figure 4. Critical orifice diameter measuring device

\subsection{Vacuum assisted flow initiation device}

The critical orifice measurement device from the section above was further developed with a chamber at the exit connected to a vacuum pump via a vacuum regulator.

The term "differential pressure" is used in this paper to describe a pressure difference between ambient pressure (above the orifice disk) and vacuum chamber (below the orifice disk). It is noted that this differential pressure has small values.

\subsubsection{System development}

A cylindrical vacuum chamber with internal diameter $D=146 \mathrm{~mm}$ and height of $H=100 \mathrm{~mm}$ made of acrylic was designed to accommodate the critical orifice measurement device and control the differential pressure at the exit, Figure 5 . A release pin of the shutter mechanism was installed on the body of the chamber allowing control of the shutter whilst maintaining differential pressure in the chamber. Two standard connecting ports were mounted on the top plate of the chamber to connect to the vacuum pump via the regulator and to a pressure transducer (Sensirion SDP1000-L). The base of the vacuum chamber was sealed with an O-ring for convenient operation of the device. 


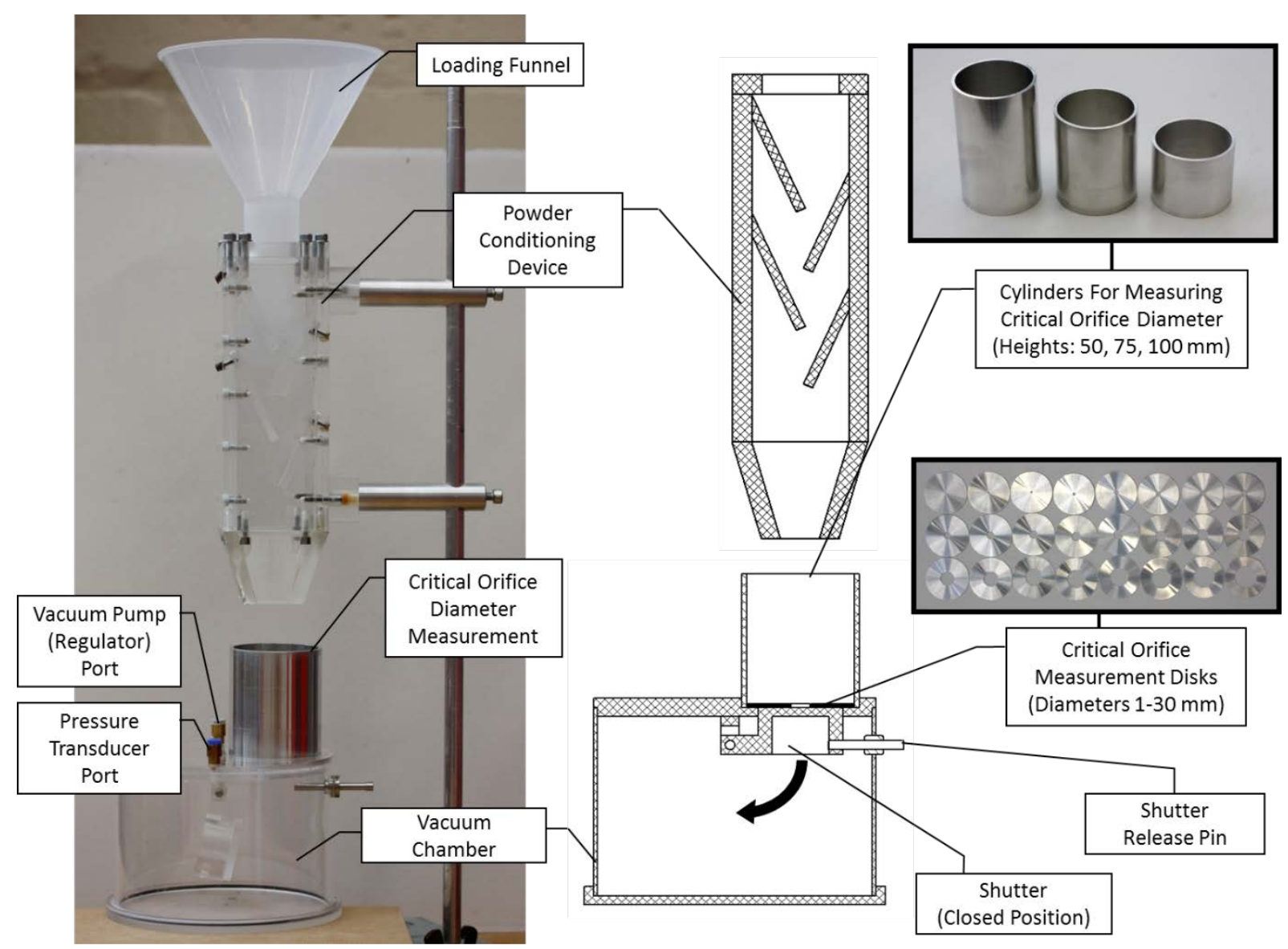

Figure 5. Vacuum assisted flow initiation device

\subsubsection{Method}

A disk with an orifice diameter smaller than the critical value was placed at the base of the cylindrical container. The powder was introduced into the container using the conditioning device and the hip formed on the top was removed using a horizontal blade to meter the same volume of powder in each experiment.

The shutter was then opened and the differential pressure was increased in the chamber using the regulator until powder flow initiated. The differential pressure was monitored using the transducer. The differential pressure at which powder flow initiated was recorded. Cylinders with three different heights $(50,75$ and $100 \mathrm{~mm}$ ) were used to examine the effect of powder height (a fresh sample of powder was used for each cylinder height). A test was repeated three times for each disk and each cylinder height.

\subsubsection{Transducer calibration}

The schematic experimental setup used to calibrate the differential pressure transducer is presented in Figure 6. The pressure inside the vacuum chamber (monitored with a calibrated manometer) was decreased by $500 \mathrm{~Pa}$ using a manual pump (pressure bulb). The differential pressure was then reduced slowly and the output voltage of the transducer was logged using a data acquisition device (by National Instruments) and PC software (LabVIEW). Using this method the calibration curve to convert the output voltage of the transducer to the corresponding differential pressure was determined. 


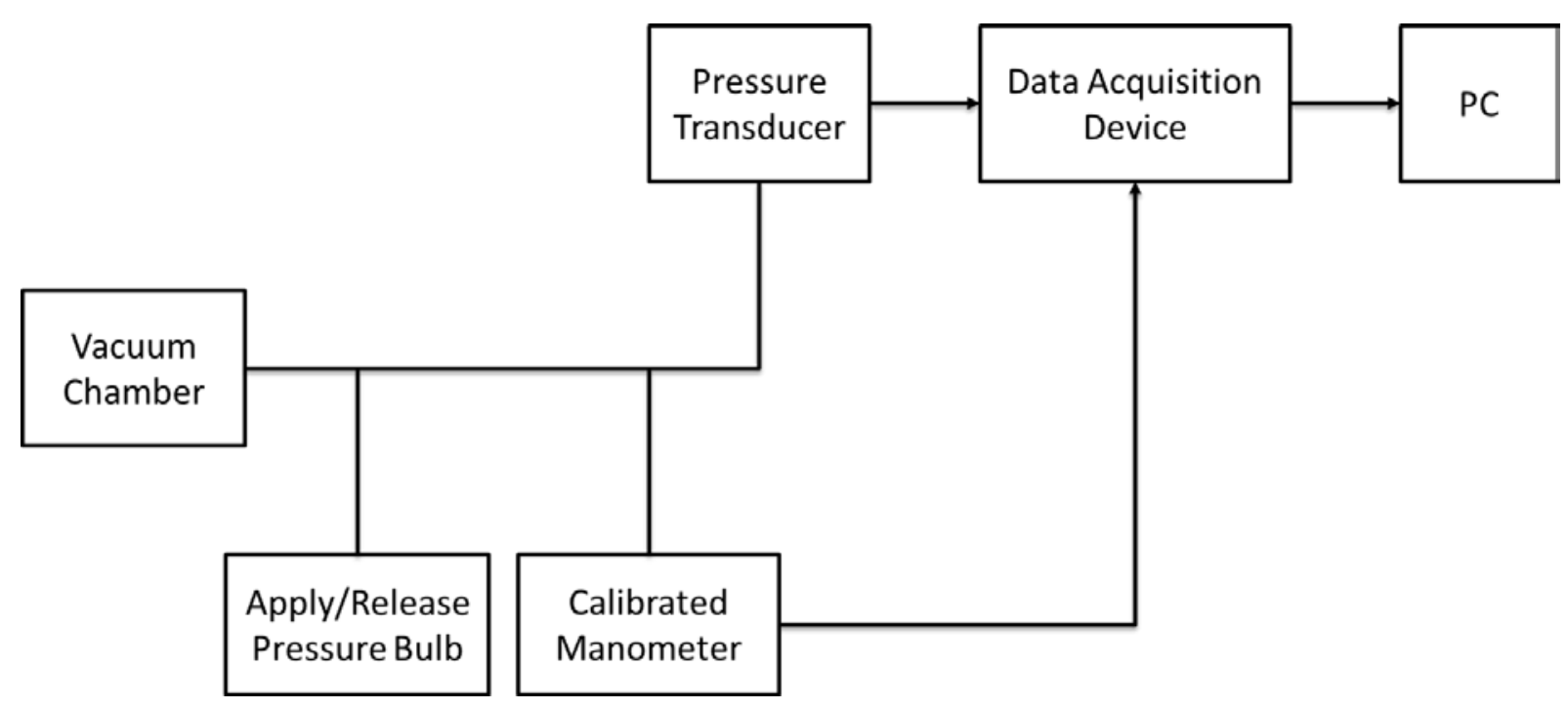

Figure 6. Schematic diagram of the pressure transducer calibration procedure

\section{Results and discussion}

In the following sections the behaviour of the powders is compared systematically with respect to particle size, bulk density and height of the powder bed above the opening.

\subsection{Flow properties using existing methods}

The standard test methods used in this section are performed in ambient atmosphere. The bulk density, critical orifice diameter and angle of repose measured for the selected grades of microcrystalline cellulose are presented in Table 2. It is observed that the critical orifice diameter changes with average particle size and bulk density. The critical orifice diameter reduces as the average particle size increases showing that larger particle size improves flowability. The results are consistent with angle of repose measurements where a lower angle of repose shows a better flowing powder.

The critical orifice diameter measured for PH302 and PH102 (which have the same average particle size but different bulk density) suggests that the denser powder flows better. However, the angle of repose shows an opposite effect of the powder density. The standard deviation for the angle of repose data presented in Table 2 is between $0.29^{\circ}-1.4^{\circ}$.

Table 2. Bulk density, critical orifice diameter and angle of repose data

\begin{tabular}{|c|c|c|c|c|c|}
\hline \multirow{2}{*}{ Material } & \multirow{2}{*}{$\begin{array}{c}\text { Bulk } \\
\text { Density, } \\
\mathrm{kg} / \mathrm{m}^{3}\end{array}$} & \multirow{2}{*}{$\begin{array}{c}\text { Critical Orifice Diameter, mm } \\
\text { (Cylinder Height 75 mm) }\end{array}$} & \multicolumn{3}{|c|}{ Angle of Repose, $^{\circ}$} \\
\cline { 4 - 6 } & 341 & 30 & $50 \mathrm{~mm}$ & $75 \mathrm{~mm}$ & $100 \mathrm{~mm}$ \\
\hline PH101 & 341 & 26 & 39 & 45 & 44 \\
\hline PH102 & 320 & 11 & 33 & 34 & 39 \\
\hline PH200 & 361 & 24 & 46 & 45 & 43 \\
\hline PH302 & 442 & & \multicolumn{3}{|c|}{} \\
\hline
\end{tabular}


The critical orifice diameter measurements in Table 2 provide the same ranking order of microcrystalline cellulose powders in terms of flowability as the results published by Hou et al. [33] obtained using a ring shear cell testing. They found that increasing particle size improves flow properties as a result of reduction in specific surface area of contacts, the van der Waal's forces and the $\mathrm{H}$-bonding between particles. The effect of bulk density was not discernible, however, by normalising the unconfined yield strength with respect to bulk density they found that powders with higher bulk density flow better [33]. This is consistent with the critical orifice results in Table 2.

The effect of particle size and shape were investigated by Fu et al. [34] for lactose powders using the shear cell method (FT4 Powder Rheometer by Freeman Technology, Tewkesbury, UK). They observed that particle shape has a more significant effect on powder flowability than particle size. Similar conclusions on the effect of particle shape were obtained by Podczeck and Miah [35] using the same shear cell method (Annular Shear Cell by Technigraph, Bristol, UK) and the Jenike flow factor [20, 21] was found to increase from needle shape, cubic, angular to round shapes.

\subsection{Effect of air pressure at discharge on flow initiation}

The average differential pressures (for the repeated experiments) required to initiate powder flow after arch formation are presented in the Appendix and plotted in Figure 7. It is observed that there exists a power relation between orifice diameter and differential pressure required to initiate flow. More importantly for practical purposes, it is seen that a small differential pressure (of the order of a 100-300 Pa) can reduce the critical orifice diameter significantly by up to 15 times (e.g. from 30 to 2 $\mathrm{mm}$ ). It is also observed that the differential pressure required for flow initiation decreases as the average particle size increases. Therefore, the powder with better flowability based on the angle of repose experiment requires a smaller differential pressure to break the arch.

The results show that the powder with higher bulk density ( $\mathrm{PH} 302)$ requires higher differential pressure for flow initiation than the powder with lower density (PH102) and the same particle size. This is opposite to the ranking given by the standard critical orifice diameter test which was performed in ambient atmosphere.

In terms of the effect of powder height above the exit $(H)$, it is evident that an increase in powder height results in an increase in the differential pressure required for flow initiation. This effect is observed for all four powders used in this study. 


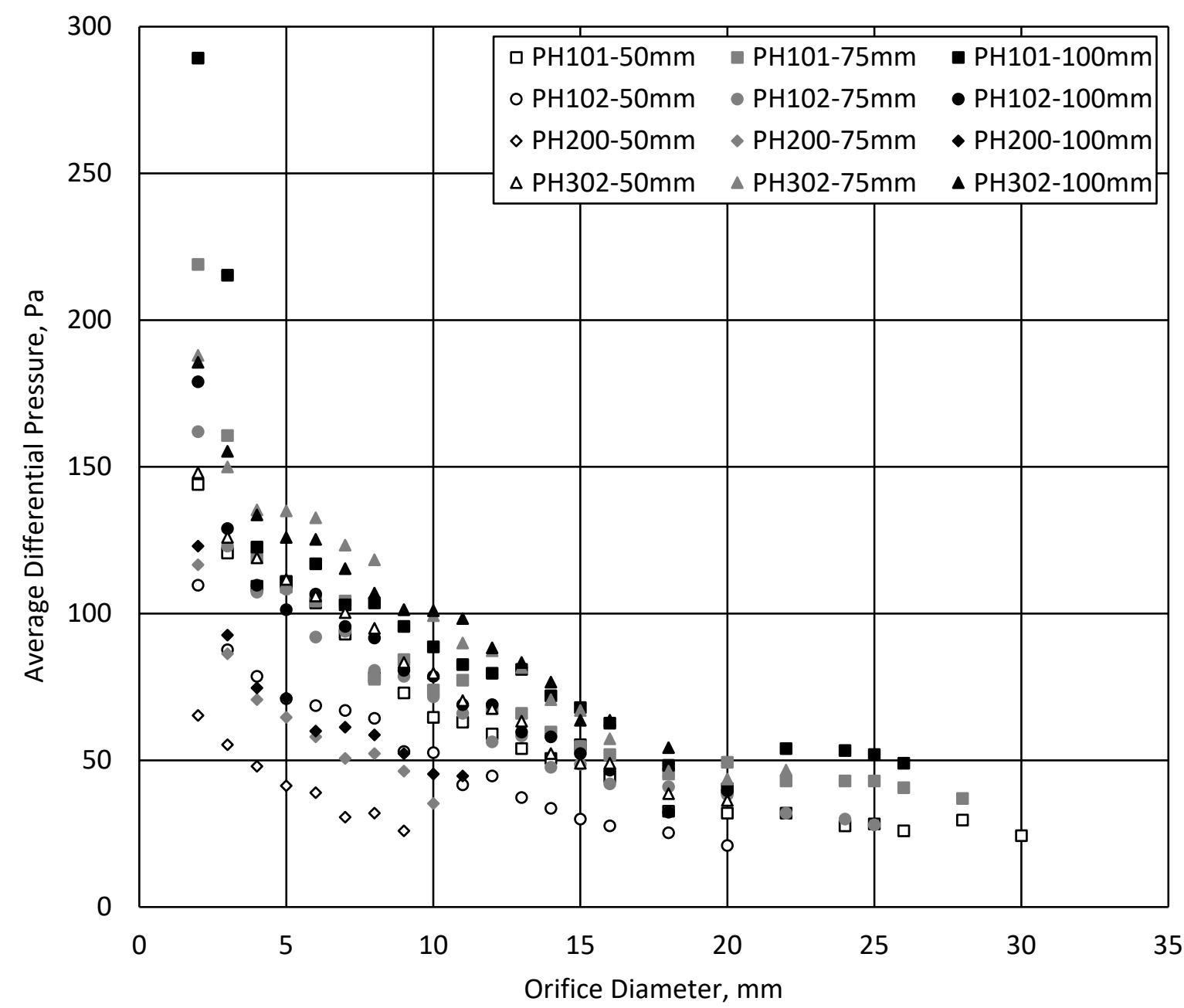

Figure 7. Orifice diameter vs. average differential pressure required to break the arch and initiate flow

\subsection{Dimensional analysis}

The parameters involved in the process are: differential pressure required to initiate powder flow $(\Delta P)$; bulk density of powder $\left(\rho_{b}\right)$; acceleration due to gravity $(g)$; particle size $(d)$; height of powder above the exit $(H)$; and orifice diameter $(D)$. There are also other parameters like viscosity of air $(\mu)$, coefficient of friction between particles $\left(\mu_{p}\right)$ and between particles and the wall $\left(\mu_{p w}\right)$, shape of the exit and adhesion between particles that contribute. Thus $\Delta P$ can be written as a function of $\rho_{b}, g, d$, $H, D, \mu, \mu_{p}, \mu_{p w}$, particle shape and adhesion i.e.

$$
\Delta P=f\left(\rho_{b}, g, d, H, D, \mu, \mu_{p}, \mu_{p w}, \text { shape, adhesion }\right)
$$

or

$$
F\left(\Delta P, \rho_{b}, g, d, H, D, \mu, \mu_{p}, \mu_{p w} \text {, shape, adhesion }\right)=0
$$

Following the Buckingham $\Pi$ theorem [36] used in dimensional analysis, by taking $\rho_{b}, g$ and $d$ as independent variables, three dimensionless groups can be formed as follows: 


$$
\begin{gathered}
\overline{\Delta P}=\frac{\Delta P}{\rho_{b} g d} \\
\bar{H}=\frac{H}{d} \\
\bar{D}=\frac{D}{d}
\end{gathered}
$$

Therefore, it can be written that

$$
\overline{\Delta P}=f\left(\bar{H}, \bar{D}, \mu, \mu_{p}, \rho_{p w}, \text { shape, adhesion }\right)
$$

The experiments show a direct relation between height of the powder above the orifice $(H)$ and the average differential pressure required for flow initiation $(\Delta P)$, and an inverse relation between the orifice diameter $(D)$ and $\Delta P$. Thus the two dimensionless groups of $\bar{H}$ and $\bar{D}$ can be combined to form a new dimensionless group

$$
\overline{\bar{D}}=\frac{H}{D}
$$

For a given powder over a range of orifices and powder heights, it is possible to fit a power law relation to the data (Figure 8)

$$
\frac{\Delta P}{\rho_{b} g d}=C\left(\frac{H}{D}\right)^{n}
$$


where $C$ and $n$ are empirical constants which depend on the material and processing parameters which are not included in the relationship.

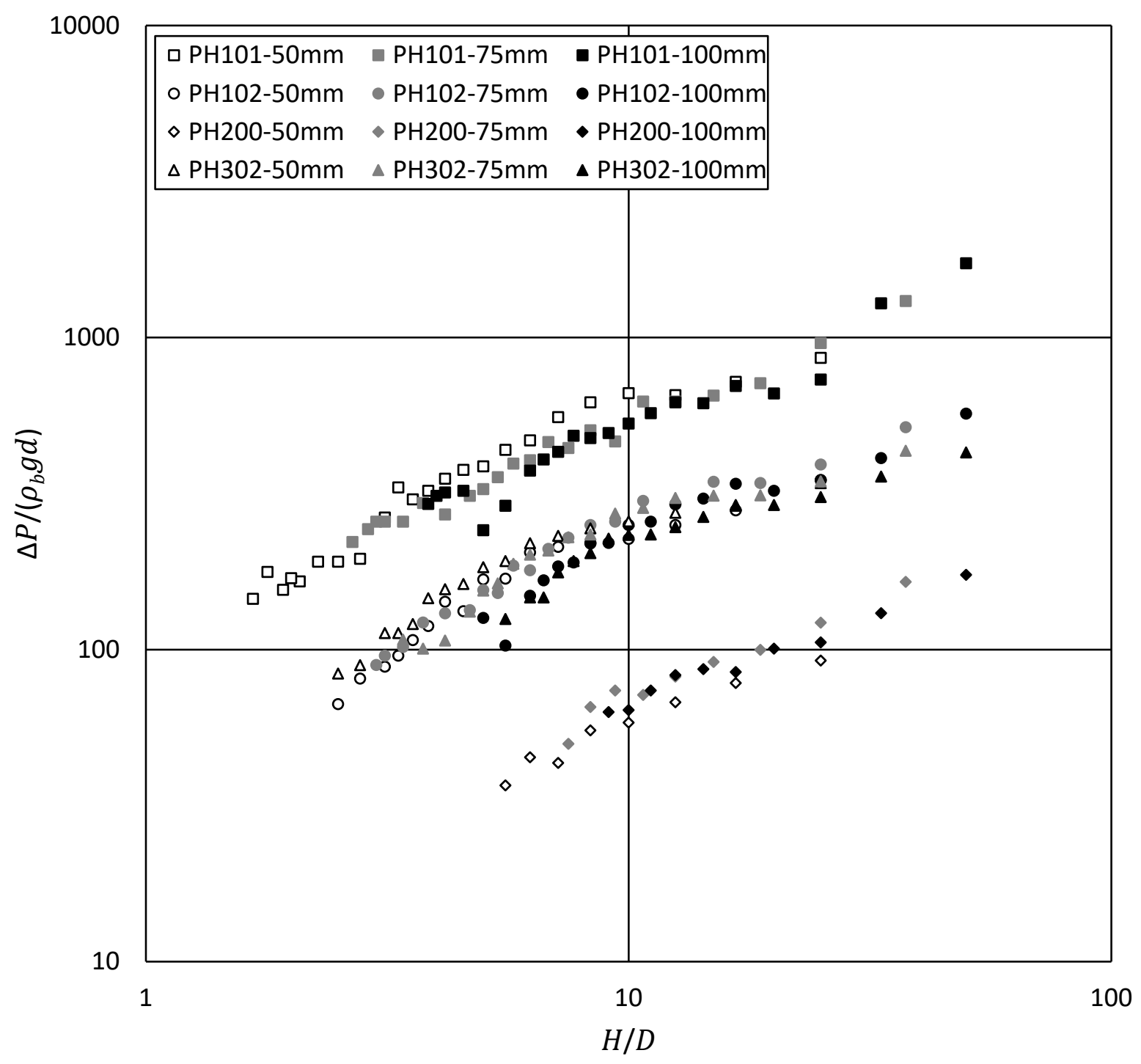

Figure 8. Power law relationship between the two dimensionless groups $H / D$ vs. $\overline{\Delta P}$ 
The values of $C$ and $n$ obtained from fitting the expression to the data are presented in Figure 9 and Table 3.

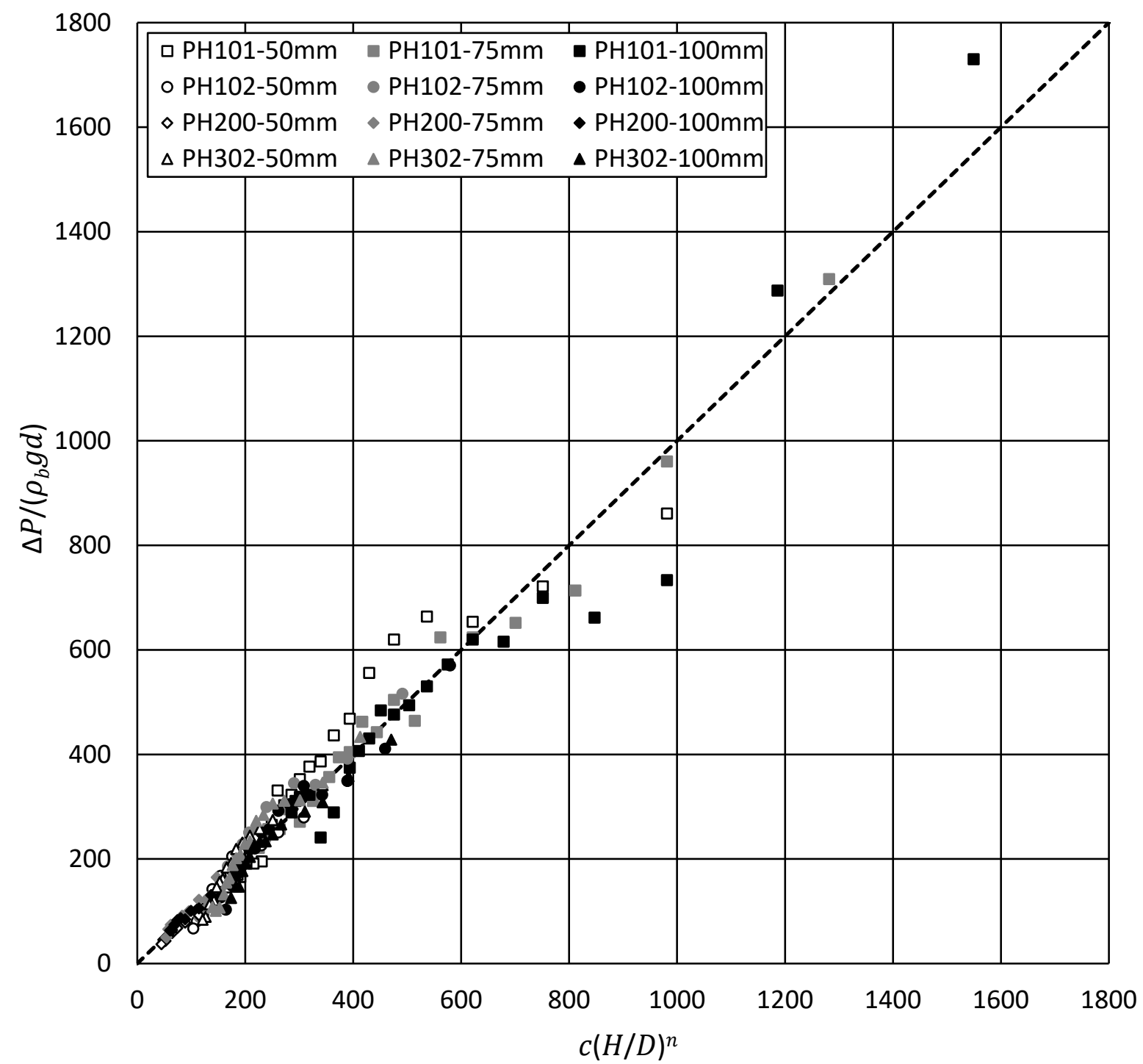

Figure 9. Plot of $C(H / D)^{n}$ vs. $\overline{\Delta P}$ based on the values of $C$ and $n$ obtained from fitting the relation on the results

Table 3. Values of $C$ and $n$ for the powders tested

\begin{tabular}{|c|c|c|}
\hline Material & $C$ & $n$ \\
\hline PH101 & 118 & 0.66 \\
\hline PH102 & 61 & 0.57 \\
\hline PH200 & 15 & 0.62 \\
\hline PH302 & 80 & 0.45 \\
\hline
\end{tabular}


Equation (8) satisfies the observations made on the effects of orifice diameter $(D)$, bulk density $\left(\rho_{b}\right)$ and height of the powder above the exit $(H)$ on the differential pressure $(\Delta P)$. However, as indicated above, a powder with higher average particle size $(d)$ requires a smaller differential pressure to initiate powder flow which is in comparison with the expression. This is due to the fact that particle size is a determining factor for other parameters involved in the process that are not considered in this study. For example, the Kozeny - Carman relationship [37, 38] links particle size to powder permeability $(k)$, where permeability is defined using Darcy's law [39].

In Equation (8) the coefficient $C$ and $n$ depend on the material dependent parameters and the processing conditions, e.g. geometry of the system. As the processing conditions (except $H$ and $D$ ) are fixed for all materials, it is instructive to set the value of $n$ to the average value $(n=0.58)$. The values of $C$ obtained for the materials using a fixed $n$ are presented in Table 4 and plotted in Figure 10. Comparing the coefficients it is seen that $C$ is inversely proportional to average particle size $(d)$. 
$\mathrm{PH} 200$ with the highest $d$ has the smallest $C$ while for $\mathrm{PH} 102$ and $\mathrm{PH} 302$ (with different bulk density but similar average particle size) the value of the coefficient is almost the same.

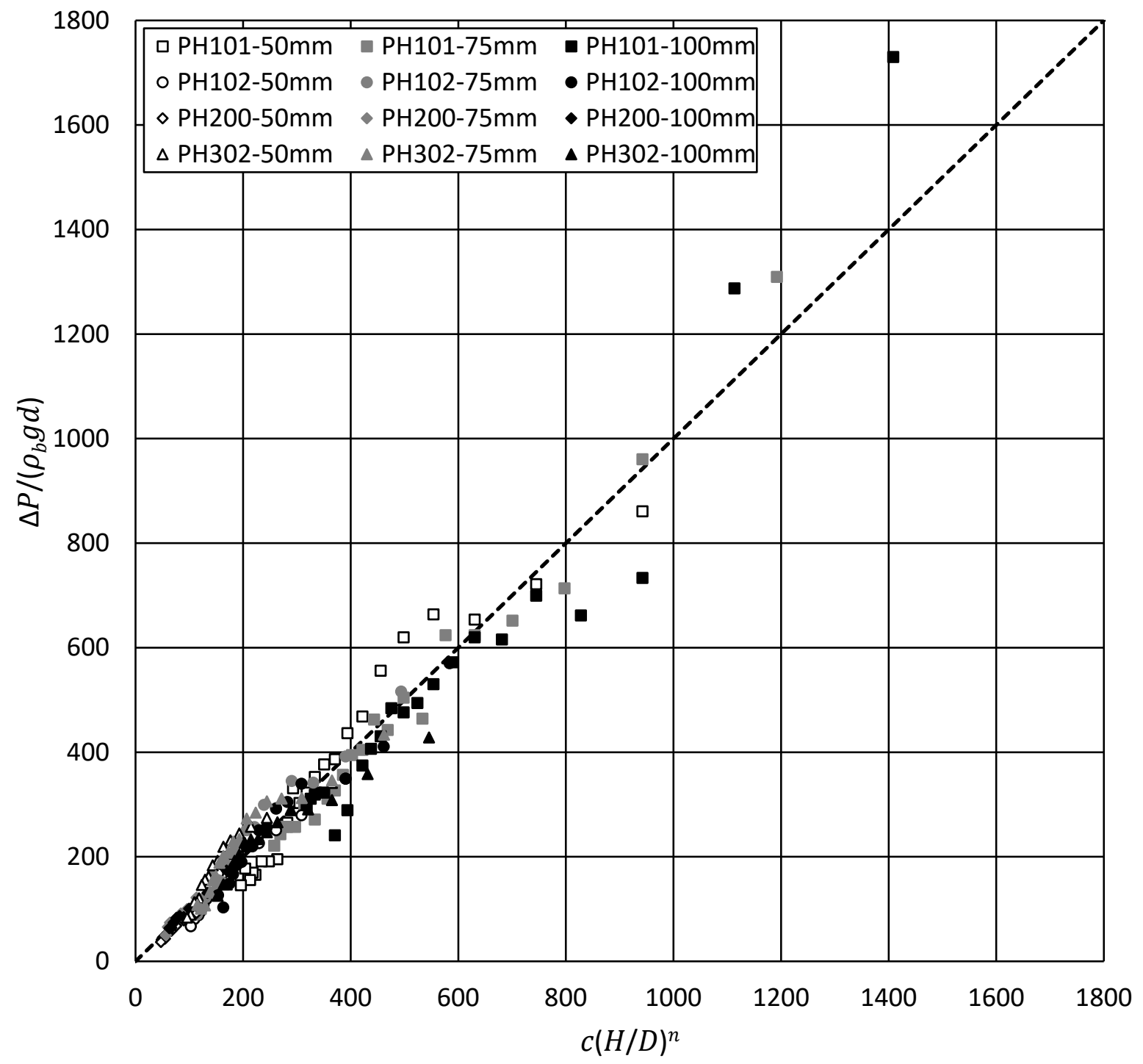

Figure 10. Plot of $C(H / D)^{n}$ vs. $\overline{\Delta P}$ based on the values of $C$ obtained for a fixed $n$

Table 4. Values of $C$ calculated from fitting the expression to the data for a fixed $n=0.58$

\begin{tabular}{|c|c|}
\hline Material & $C$ \\
\hline PH101 & 146 \\
\hline PH102 & 61 \\
\hline PH200 & 18 \\
\hline PH302 & 56 \\
\hline
\end{tabular}


Once the arch formed the powder bed was broken and the powder was discharged, three different mechanisms for the remaining powder in the container were observed (Figure 11). The mechanism depends on the size of the exit and powder flowability. Generally for large exit diameters mechanism $(b)$ is observed for all powders. For PH101 and PH302, which are ranked as poor flowing compared to other materials based on the angle of repose experiment, a transition to mechanism (c) and then $(d)$ is observed by reducing the exit diameter. However for PH200 with the best flowability, mechanism $(b)$ was the only mechanism observed. Mechanism $(d)$ suggest the tendency of poor flowing powder to form arches which are broken by the applied differential pressure.

For all powders flowing under the effect of differential pressure it was observed that if the differential pressure was removed then the arch re-formed instantaneously. This indicates that differential pressure is necessary not only for flow initiation but also to maintain the flow.

The particle properties that influence flow (e.g. inter-particulate fiction and adhesion) are included in the analysis in the parameter list of Equation (1). The contributions originate from interactions between particles at much smaller scale than considered in this work. However, it is important to consider that the flow behaviour of powders is dependent not only on particle properties but also on process conditions. 

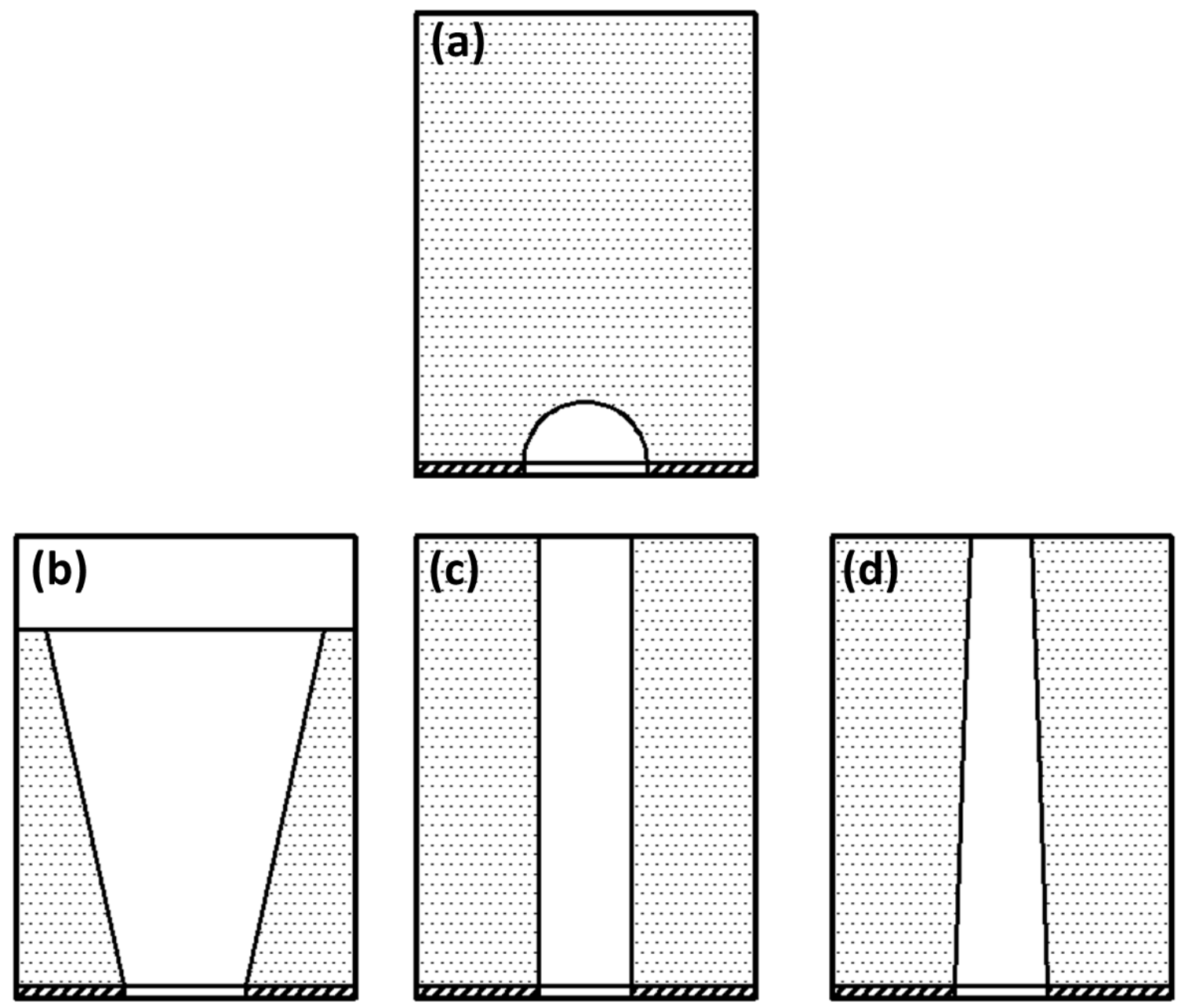

High

Flowability

Low

\section{Orifice Diameter}

Figure 11. Schematic diagram of flow patterns; a) initial state (arching), b) mechanisms for good flowing powder and large orifice diameters, $c$ ) transition regime, d) mechanism for poor flowing powders and small exit diameters after discharge under differential pressure

\section{Conclusions}

This research examined the effect of differential pressure conditions on powder flow initiation from an arching state. Arch stability is very sensitive to small variations of pressure. Specifically, it was demonstrated that if the air pressure at the exit is reduced by only a small amount, of the order of $100 \mathrm{~Pa}$ (the atmospheric pressure is $100,000 \mathrm{~Pa}$ ) then it was possible to reduce the critical orifice diameter significantly. This result has significant practical implications for handling and dosing of fine powders.

A dimensional model was developed to calculate the pressure difference $(\Delta P)$ required to initiate flow for a given exit diameter. Equation (8) contains two dimensionless groups (one related to the 
powder properties and one related to the geometry of the system) and two empirical parameters $(C, n)$ which can be determined using simple experiments.

For practical use Equation (8) can be calibrated using the system presented in Figure 5 by performing 2 experiments to determine the slope and the off-set of the logarithmic relationship in Figure 8. Parameter $C$ includes powder specific properties, including particle size and more detailed experiments are required to isolate the effect of these properties.

The results also show that different powder flowability measurement methods give different ranking of powders. A powder flow method is typically designed to characterise a given behaviour, thus the selection of the measurement method should be made with consideration of the actual powder flow process under investigation. Equation (8) can be used in process design provided that the material specific parameter $C$ was determined experimentally. The potential practical impact of the proposed flow model is significant in terms of predicting flow initiation and offering a measure for powder flowability.

\section{Acknowledgment}

The powders used in this work were gift from FMC Biopolymer, Belgium.

\section{References}

1. Brown, R.N., et al., Interband Magnetoreflection in Bismuth. II. Low Fields. Physical Review Letters, 1960. 5(6): p. 243-246.

2. Rose, H.F. and T. Tanaka, Rate of Discharge of Granular Materials from Bins an Hoppers. The Engineer (London) 1959.

3. Fowler, R.T. and J.R. Glastonbury, The flow of granular solids through orifices. Chemical Engineering Science, 1959. 10(3): p. 150-156.

4. Beverloo, W.A., H.A. Leniger, and J. van de Velde, The flow of granular solids through orifices. Chemical Engineering Science, 1961. 15(3-4): p. 260-269.

5. USP29-NF24, United States Pharmacopeia [and] National Formulary. 2006: United States Pharmacopeial Convention.

6. Podczeck, F. and B.E. Jones, Pharmaceutical Capsules. 2004: Pharmaceutical Press.

7. Walker, D.M., An approximate theory for pressures and arching in hoppers. Chemical Engineering Science, 1966. 21(11): p. 975-997.

8. Jenike, A.W., Storage and flow of solids, bulletin no. 123. Bulletin of the University of Utah, 1964. 53(26).

9. Schulze, D., Flow properties of powders and bulk solids. Braunschweig/Wolfenbu ttel, Germany: University of Applied Sciences, 2006.

10. ASTM C1444-00, Standard Test Method for Measuring the Angle of Repose of Free-Flowing Mold Powders (Withdrawn 2005), in Annual Book of ASTM Standards. 2000: ASTM International, West Conshocken, PA.

11. Carr, R.L., Evaluating flow properties of solids. 1965.

12. Carrigy, M.A., EXPERIMENTS ON THE ANGLES OF REPOSE OF GRANULAR MATERIALS1. Sedimentology, 1970. 14(3-4): p. 147-158.

13. Geldart, D., et al., Characterization of powder flowability using measurement of angle of repose. China Particuology, 2006. 4(3-4): p. 104-107. 
14. Cornforth, D., Prediction of drained strength of sands from relative density measurements. ASTM special technical publication, 1973. 523: p. 281-303.

15. Pascale, C.R., Comparison of Methods for the Measurement of the Angle of Repose of Granular Materials. 2013.

16. Santamarina, J.C. and G.C. Cho, Determination of critical state parameters in sandy soilssimple procedure. Geotechnical testing journal, 2001. 24(2): p. 185-192.

17. Geldart, D., M. Mallet, and N. Rolfe. Assessing the flowability of powders using angle of repose. in Powder Handling \& Proc. 1990.

18. Lee, Y.L., et al., Development of a dual approach to assess powder flow from avalanching behavior. AAPS PharmSciTech, 2000. 1(3): p. 44-52.

19. Hassanpour, A. and M. Ghadiri, Characterisation of Flowability of Loosely Compacted Cohesive Powders by Indentation. Particle \& Particle Systems Characterization, 2007. 24(2): p. 117-123.

20. Jenike, A.W., Gravity Flow of Bulk Solids. 1961: Bulletin No. 108, Utah State University.

21. Jenike, A.W., Quantitative design of mass-flow bins. Powder Technology, 1967. 1(4): p. 237244.

22. Drescher, A., A.J. Waters, and C.A. Rhoades, Arching in hoppers: I. Arching theories and bulk material flow properties. Powder Technology, 1995. 84(2): p. 165-176.

23. Drescher, A., A.J. Waters, and C.A. Rhoades, Arching in hoppers: II. Arching theories and critical outlet size. Powder Technology, 1995. 84(2): p. 177-183.

24. Shinohara, K., E. Suzuki, and T. Tanaka, EFFECT OF AIR PRESSURE ON FLOW CRITERION OF COHESIVE POWDERS FROM A HOPPER. Journal of Chemical Engineering of Japan, 1973. 6(1): p. 84-91.

25. Bulsara, P.U., F.A. Zenz, and R.A. Eckert, Pressure and Additive Effects on Flow of Bulk Solids. Industrial \& Engineering Chemistry Process Design and Development, 1964. 3(4): p. 348-355.

26. Sinka, I.C., L.C.R. Schneider, and A.C.F. Cocks, Measurement of the flow properties of powders with special reference to die fill. International Journal of Pharmaceutics, 2004. 280(1-2): p. 2738.

27. Wu, C.-Y., L. Dihoru, and A.C.F. Cocks, The flow of powder into simple and stepped dies. Powder Technology, 2003. 134(1-2): p. 24-39.

28. Schneider, L.C.R., I.C. Sinka, and A.C.F. Cocks, Characterisation of the flow behaviour of pharmaceutical powders using a model die-shoe filling system. Powder Technology, 2007. 173(1): p. 59-71.

29. Jackson, S., I.C. Sinka, and A.C.F. Cocks, The effect of suction during die fill on a rotary tablet press. European Journal of Pharmaceutics and Biopharmaceutics, 2007. 65(2): p. 253-256.

30. Mills, L.A. and I.C. Sinka, Effect of particle size and density on the die fill of powders. European Journal of Pharmaceutics and Biopharmaceutics, 2013. 84(3): p. 642-652.

31. Katdare, A. and M. Chaubal, Excipient development for pharmaceutical, biotechnology, and drug delivery systems. 2006: CRC Press.

32. International Organization for Standardization, ISO 4490: Metallic powders - Determination of flow rate by means of a calibrated funnel (Hall flowmeter). 2014.

33. Hou, H. and C.C. Sun, Quantifying effects of particulate properties on powder flow properties using a ring shear tester. Journal of pharmaceutical sciences, 2008. 97(9): p. 4030-4039.

34. $\mathrm{Fu}, \mathrm{X}$. , et al., Effect of particle shape and size on flow properties of lactose powders. Particuology, 2012. 10(2): p. 203-208.

35. Podczeck, F. and Y. Mia, The influence of particle size and shape on the angle of internal friction and the flow factor of unlubricated and lubricated powders. International Journal of Pharmaceutics, 1996. 144(2): p. 187-194.

36. Gibbings, J.C., Dimensional analysis. 2011: Springer Science \& Business Media.

37. Kozeny, J., Über kapillare Leitung des Wassers im Boden:(Aufstieg, Versickerung und Anwendung auf die Bewässerung). 1927: Hölder-Pichler-Tempsky. 
38. Carman, P., Fluid flow through granular beds. Transactions-Institution of Chemical Engineeres, 1937. 15: p. 150-166.

39. Darcy, H., Les fontaines publiques de la ville de Dijon: exposition et application. 1856: Victor Dalmont. 
Appendix. Averaged differential pressures measured for each exit diameter

\begin{tabular}{|c|c|c|c|c|c|c|c|c|c|c|c|c|}
\hline \multirow{3}{*}{$\begin{array}{c}\text { orifice } \\
\text { diameter } \\
(\mathrm{mm})\end{array}$} & \multicolumn{12}{|c|}{ Meterial } \\
\hline & \multicolumn{3}{|c|}{ PH101 } & \multicolumn{3}{|c|}{ PH102 } & \multicolumn{3}{|c|}{ PH2O0 } & \multicolumn{3}{|c|}{ PH302 } \\
\hline & $50 \mathrm{~mm}$ & $75 \mathrm{~mm}$ & $100 \mathrm{~mm}$ & $50 \mathrm{~mm}$ & $75 \mathrm{~mm}$ & $100 \mathrm{~mm}$ & $50 \mathrm{~mm}$ & $75 \mathrm{~mm}$ & $100 \mathrm{~mm}$ & $50 \mathrm{~mm}$ & $75 \mathrm{~mm}$ & $100 \mathrm{~mm}$ \\
\hline 2 & 144 & 219 & 289 & 110 & 162 & 179 & 65 & 117 & 123 & 148 & 188 & 186 \\
\hline 3 & 121 & 161 & 215 & 88 & 123 & 129 & 55 & 86 & 93 & 126 & 150 & 155 \\
\hline 4 & 109 & 119 & 123 & 79 & 107 & 110 & 48 & 71 & 75 & 119 & 135 & 134 \\
\hline 5 & 111 & 109 & 111 & 71 & 108 & 101 & 41 & 65 & 71 & 112 & 135 & 126 \\
\hline 6 & 104 & 104 & 117 & 69 & 92 & 107 & 39 & 58 & 60 & 106 & 133 & 125 \\
\hline 7 & 93 & 104 & 103 & 67 & 94 & 96 & 31 & 51 & 61 & 100 & 123 & 115 \\
\hline 8 & 78 & 78 & 104 & 64 & 81 & 92 & 32 & 52 & 59 & 95 & 118 & 107 \\
\hline 9 & 73 & 84 & 96 & 53 & 79 & 81 & 26 & 46 & 52 & 83 & 101 & 101 \\
\hline 10 & 65 & 74 & 89 & 53 & 72 & 79 & - & 35 & 45 & 80 & 99 & 101 \\
\hline 11 & 63 & 77 & 83 & 42 & 66 & 69 & - & - & 45 & 70 & 90 & 98 \\
\hline 12 & 59 & 68 & 80 & 45 & 56 & 69 & - & - & - & 68 & 87 & 88 \\
\hline 13 & 54 & 66 & 81 & 37 & 58 & 60 & - & - & - & 63 & 82 & 83 \\
\hline 14 & 51 & 60 & 72 & 34 & 48 & 58 & - & - & - & 52 & 71 & 77 \\
\hline 15 & 55 & 55 & 68 & 30 & 49 & 52 & - & - & - & 49 & 67 & 64 \\
\hline 16 & 44 & 52 & 63 & 28 & 42 & 47 & - & - & - & 49 & 57 & 64 \\
\hline 18 & 33 & 45 & 48 & 25 & 41 & 32 & - & - & - & 39 & 46 & 54 \\
\hline 20 & 32 & 49 & 40 & 21 & 38 & 40 & - & - & - & 36 & 44 & - \\
\hline 22 & 32 & 43 & 54 & - & 32 & - & - & - & - & - & 47 & - \\
\hline 24 & 28 & 43 & 53 & - & 30 & - & - & - & - & - & - & - \\
\hline 25 & 28 & 43 & 52 & - & 28 & - & - & - & - & - & - & - \\
\hline 26 & 26 & 41 & 49 & - & - & - & - & - & - & - & - & - \\
\hline 28 & 30 & 37 & - & - & - & - & - & - & - & - & - & - \\
\hline 30 & 24 & - & - & - & - & - & - & - & - & - & - & - \\
\hline
\end{tabular}

